\title{
Effects of salinity on the survival of the Brackwater mussel, Brachidontes virgiliae, in the St Lucia estuarine system, South Africa
}

\author{
HA Nel ${ }^{1 *}$, R Perissinotto ${ }^{2,1}$ and RH Taylor ${ }^{3,1}$ \\ 'School of Life Sciences, University of KwaZulu-Natal, Westville Campus, P. Bag X54001, Durban 4000, South Africa \\ ${ }^{2}$ DST/NRF Research Chair in Shallow Water Ecosystems, Nelson Mandela Metropolitan University, P.O. Box 77000, Port Elizabeth 6031, South Africa \\ ${ }^{3}$ Ezemvelo KZN Wildlife, P. Bag X01, St Lucia Estuary 3936, South Africa
}

\begin{abstract}
During drought periods, the razor clam Solen cylindraceus is the dominant bivalve in the St Lucia estuarine system, although restricted to its South Lake region. However, with the recent onset of a wet phase, the mussel Brachidontes virgiliae has become widespread and overwhelmingly dominant throughout the system. The salinity tolerance of $B$. virgiliae is here determined using both rapid and gradual changes in salinity. Mussels were collected at Esengeni in the Narrows (salinity $\approx 0$ ) and Lister's Point in False Bay (salinity $\approx 20$ ). Mortalities were recorded for animals exposed to a sudden change in salinity using 8 different treatments, ranging from 0 to 70 . Additionally, animals were exposed to a gradual change in salinity, using treatments that exceeded the minimum and maximum salinities mussels were previously able to tolerate. In all four experiments, animals were able to tolerate salinity levels up to 20 . However, a wider salinity tolerance, up to 50 , was shown by animals collected from Lister's Point and those gradually acclimated to test conditions. With an increase in flood events predicted for this region, it is imperative to understand how key species may be affected. During wet phases $B$. virgiliae becomes ubiquitious throughout Lake St Lucia and it is unlikely that the species will disappear from the system, even if floods escalate in the future, as it has an ability to withstand near-freshwater conditions. During dry periods, however, the mussel will be concentrated in the Narrows (oligohaline to limnetic conditions), especially if an inverse salinity gradient with hypersaline conditions prevails within the system.
\end{abstract}

Keywords: bivalves, range shift, wet and dry periods, hypersaline conditions, flood events, iSimangaliso Wetland Park

\section{INTRODUCTION}

Salinity is an important factor structuring the estuarine ecosystem (McLeod and Wing, 2008). This is manifested as spatial and temporal variations in salinity modify species composition and distribution within an estuary (Boltt, 1975; Cyrus, 1988; Owen and Forbes, 1997; Pillay and Perissinotto, 2008). The salinity regimes of many estuaries have been severely altered by anthropogenic modifications within their catchments (e.g. The Coorong System in Australia and the St Lucia estuarine system in South Africa). As a result of low freshwater inflow into the Coorong, a reverse salinity gradient and hypersaline conditions have developed, causing benthic invertebrates to become restricted to the lower reaches (Rolston and Dittmann, 2009). Similarly, an impoverished benthic community due to extreme hypersaline conditions is often present in the northern reaches of Lake St Lucia (Day et al., 1954; Millard and Broekhuysen, 1970; Boltt, 1975; Pillay and Perissinotto, 2008).

Although Lake St Lucia is naturally variable, exhibiting large-scale temporal changes from wet to dry periods, the dry periods have been exacerbated by the artificial divergence of the adjacent Mfolozi River into the sea (Begg, 1978; Forbes and Cyrus, 1993; Whitfield and Taylor, 2009). This has deprived Lake St Lucia of its most essential freshwater source (Forbes

\footnotetext{
* To whom all correspondence should be addressed.

Current address: Department of Zoology and Entomology, Rhodes

University, PO Box 94, Grahamstown 6140, South Africa

푱 +27 72 805-2141; e-mail: hollynel1988@gmail.com

Received 29 January 2014; accepted in revised form 14 November 2014
}

and Cyrus, 1993), which is fundamental to maintaining lake levels during dry periods and mitigating the occurrence of hypersaline events (Whitfield and Taylor, 2009). As a result, the system has experienced crises for extended periods, the last from 2002 to 2011. A reverse salinity gradient develops during dry periods, with salinities as high as 200 in the northern reaches recorded on numerous occasions (Forbes and Cyrus, 1993; Cyrus et al., 2010). A unique halotolerant community can be established in the northern reaches of the estuarine system, as few species are able to tolerate such salinity extremes (Carrasco and Perissinotto, 2012).

In addition, Lake St Lucia also experiences stochastic disturbances, such as flooding events and the presence of wetter than normal years (Cyrus, 1988; Forbes and Cyrus, 1992; Pillay and Perissinotto, 2008), both causing dramatic decreases in salinity. Cyclones Domonia and Imboa in 1984 resulted in a large-scale decline in salinity that caused the disappearance and re-distribution of most benthic species (Cyrus, 1988; Forbes and Cyrus, 1992; Owen and Forbes, 1997). In November/December 2010, Lake St Lucia received high rainfall, resulting in a drastic salinity reduction within the system (Nel et al., 2013). Additionally, the management decision to no longer keep the Mfolozi separated from Lake St Lucia (Whitfield et al., 2013) allowed the re-linkage of the two systems in July 2012. Therefore, Lake St Lucia shifted into a wet period resulting in the system becoming dominated by an oligohaline environment $(<5)$. This caused the disappearance of the infaunal bivalve, Solen cylindraceus, from the South Lake and the successful re-establishment of this species in False Bay (Fig. 1), where the salinity fell within the species tolerance range (Nel et al., 2011; Nel et al., 2013). 
During drought conditions, S. cylindraceus is considered to be the dominant bivalve species in Lake St Lucia (Nel et al., 2011; Nel et al., 2013). Although restricted to the South Lake, it occurs at high densities ranging from 14 to 3000 ind $\cdot \mathrm{m}^{-2}(\mathrm{Nel}$ et al., 2011). During the last hypersaline phase, S. cylindraceus was a key species for the system. Having a salinity tolerance between 15 and 65 , it was able to withstand high salinities outside the tolerance range of other bivalve species (Nel et al., 2011). Currently, however, the mussel Brachidontes virgiliae has become so abundant and widespread throughout Lake St Lucia that it has replaced $S$. cylindraceus as the dominant bivalve in the system. Anecdotal evidence suggests that this ubiquitous mussel is able to withstand very low salinity levels and can rapidly invade denuded areas. Therefore, this study set out to investigate the experimental salinity tolerance of the B. virgiliae population currently occurring in the St Lucia estuarine system.

A species may have two types of controls on its tolerance ranges; genetic and phenotypic (Segnini de Bravo et al., 1998). The former is defined as the genetically imposed capability to withstand an external factor, while the latter is the ability to alter its tolerance in response to previously experienced conditions (Segnini de Bravo et al., 1998). Thus, an extreme or moderate change in salinity may yield varying adaptive potentials for a species (Berger and Kharazova, 1997). Castagna and Chanley (1973) showed that a gradual change in salinity may allow a species to extend its environmental threshold. It is well established that a slow increase in salinity enables organisms to widen their tolerance range. However, there is less evidence to show that a species found in two habitats under different salinity regimes may exhibit different salinity tolerance ranges. Thus, the objectives of this study were to determine the salinity tolerances of B. virgiliae collected from two sites within Lake St Lucia and exposed to both sudden and gradual changes in salinity.

\section{METHODS AND MATERIALS}

\section{Sample collection and maintenance}

Mussels with a mean shell length of $9.76 \pm 1.06$ (SD) mm were collected from 2 sites representing the minimum and maximum salinities found within Lake St Lucia - Esengeni (salinity $\approx 0$ ) and Lister's Point (salinity $\approx 20$ ). At both sites Brachidontes virgiliae were found attached to submerged macrophytes, which were subsequently removed. They were then placed in buckets containing naturally-occurring estuarine water and transported back to the laboratory where they were aerated within 3 to $4 \mathrm{~h}$ and acclimated to laboratory conditions for 3 days, prior to their exposure to experimental conditions. During acclimation, animals were maintained at salinity levels similar to those found at the collection site. This was measured using a portable refractometer (Atago S/Mill-E). At ambient temperature, mussels were exposed to a 12:12 h light:dark regime using artificial light. Dead mussels were removed daily, to avoid contamination of the sample stock, and animals were selected randomly from the holding buckets at the start of each experiment. All experiments took place between March and August 2013.

\section{Shock experiments}

Animals collected at each of the two sites were exposed to a rapid change in salinity. Five animals were transferred into each replicate, with five replicates per salinity for the Lister's Point experiment and three for Esengeni. This was due to the availability of animals at the time. Mussels were placed into $300-\mathrm{m} \ell$ plastic

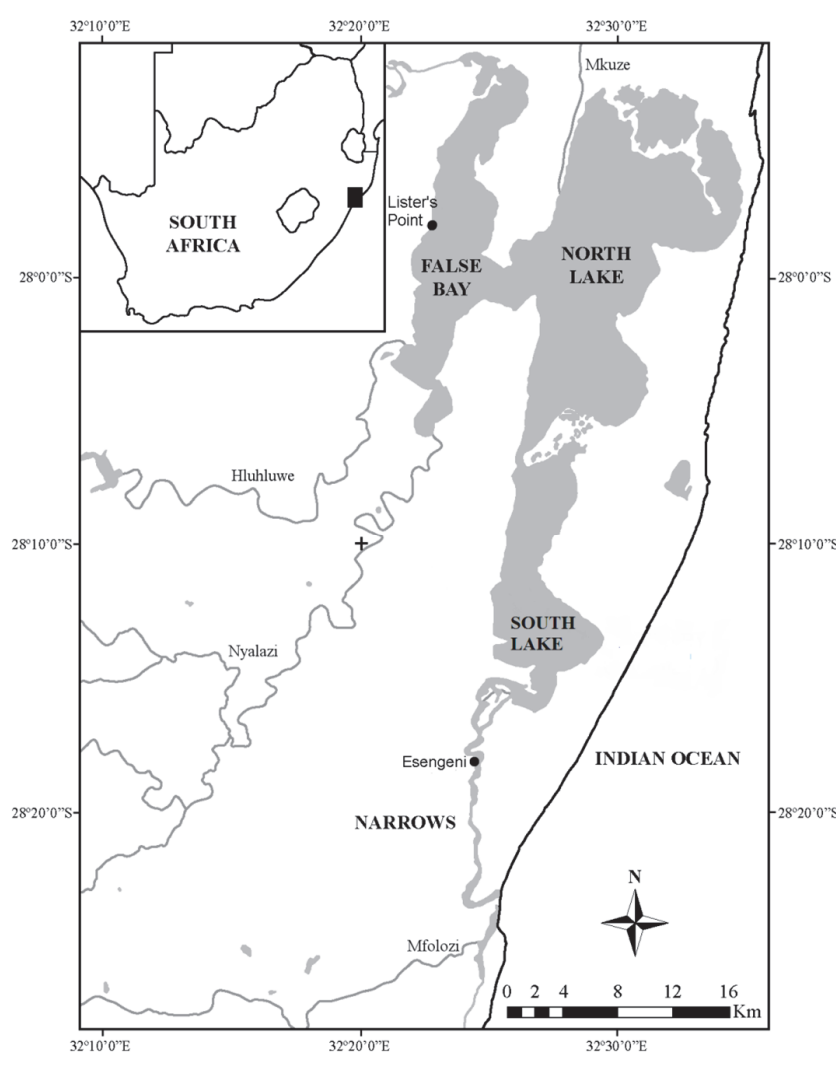

Figure 1

Map of the St Lucia estuarine system, showing localities mentioned in the text (adapted from Carrasco and Perissinotto, 2012).

bottles containing pre-made, aerated saline solutions prepared using 'Instant Marine' artificial seawater salt and fresh/distilled water. The salinity treatments ranged from 0 to 70 , increasing by increments of 10. Mortality was checked at 1,2, 4, 8, 16 and $24 \mathrm{~h}$ during the first day; thereafter daily for the next 29 days. Measured using a portable refractometer, salinity was maintained at a constant level $( \pm 1)$ and mussels were fed a suspension of naturally-occurring benthic microalgae, renewed once a week. Mussels that remained gaping and did not respond to physical stimulation were deemed to be dead.

\section{Acclimation experiments}

Fresh animals were collected from Esengeni and Lister's Point for the acclimation experiments and gradually exposed to an increase in salinity over a period of 30 days. However, the treatments used were restricted to those salinity levels that did not show $100 \%$ survival after 30 days in the previous shock experiments. Lister's Point animals were exposed to a change in salinity of 5 units every 7.5, 5, 4 and 3 days for treatment 40, 50, 60 and 70, respectively. Treatments 30, 40, 50, 60 and 70 for the Esengeni experiment were exposed to a change in salinity of 5 units every 5, 4, 3, 2.5 and 2 days, respectively. Mortality was checked daily and salinities were again maintained at a constant level ( \pm 1$)$ using a portable refractometer. Thereafter, the same set-up used for the shock experiments was employed.

\section{Analysis of data}

SigmaPlot version 11.0 was used to generate the graphs for all four experiments. A repeated-measures ANOVA was used to 


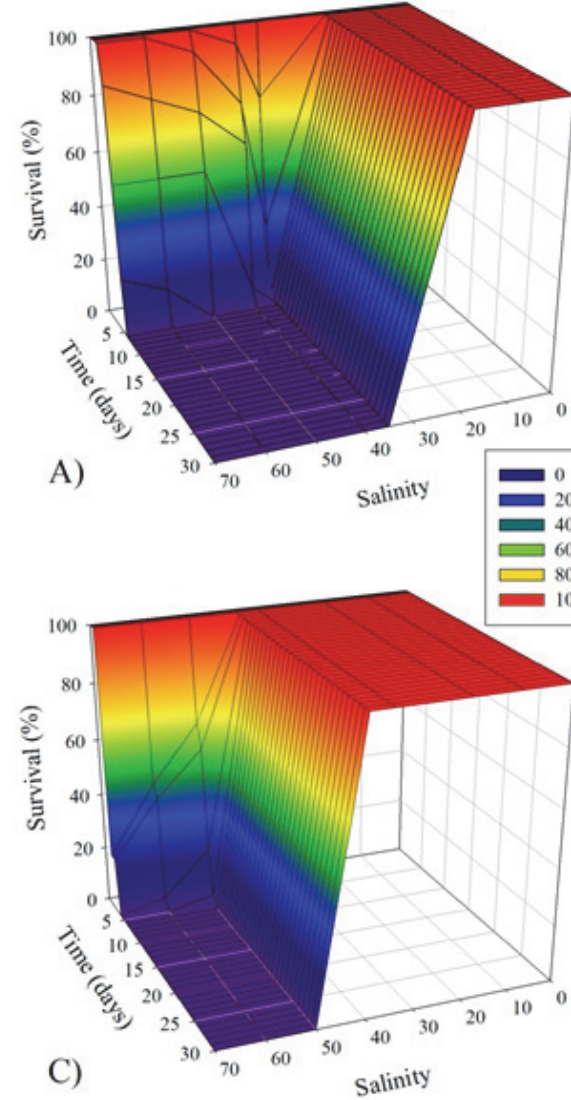

C) Salinity
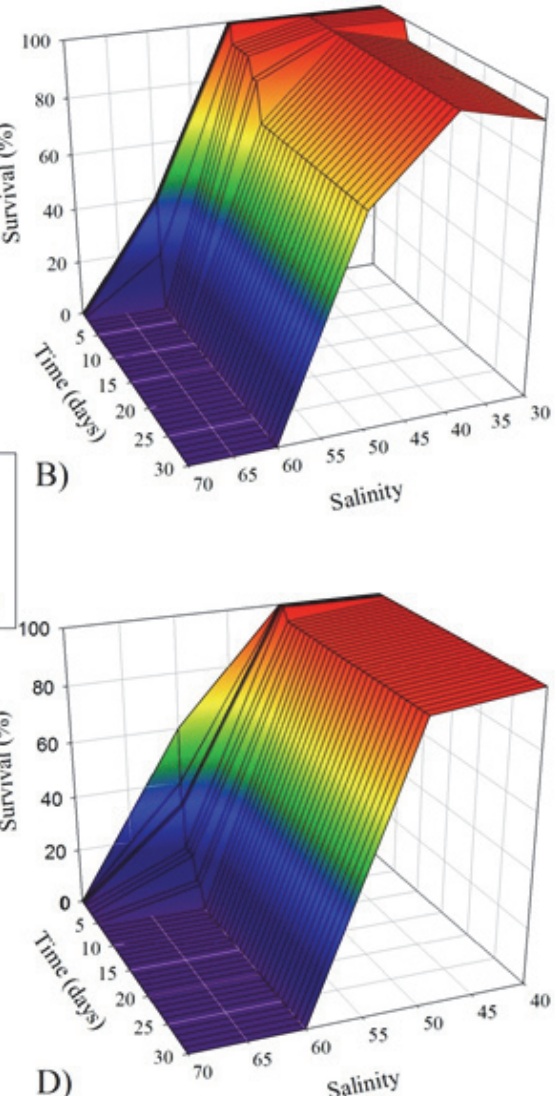

Figure 2

Percent survival of Brachidontes virgiliae exposed to varying salinity treatments ranging between 0 and 70 for a 30-day period. Mussels were: A) collected at Esengeni (freshwater conditions) and exposed to a rapid change in salinity; B) collected at Esengeni and gradually brought to test conditions; $\mathrm{C}$ ) collected at Lister's Point (salinity $\approx 20$ ) and exposed to a rapid change in salinity; D) collected at Lister's Point and gradually brought to test conditions. determine whether salinity, exposure time and the combination of the two variables had a significant effect on animal survival. In all experiments, the fixed independent variable (time) was the within-subject factor and the fixed independent variable (salinity) was the between-subject factor. Measure name was 'survival' in all analyses. In all experiments there were 36 levels (groups $=$ time). The Mauchly's Test of Sphericity was used to test the assumption that the variance was equal between the differences in all combinations of related groups (levels). The assumptions were not met and, therefore, the GreenhouseGeisser Epsilon value was used instead. SPSS 21.0 for Windows was used for all statistical analyses.

\section{RESULTS}

Brachidontes virgiliae was recorded throughout Lake St Lucia at salinities ranging from near-freshwater to $\sim 20$. The salinity maximum was recorded at Lister's Point in the northern reaches, while the minimum was found at Esengeni in the Narrows (Fig. 1). Esengeni mussels exposed to a rapid change in salinity exhibited a narrow tolerance range. Visible movement was seen in the salinity treatments ranging from 0 to 20 , with $100 \%$ survival at the end of the experiment (Fig. 2A). Unable to survive salinities above 20, animals exposed to levels above this threshold remained tightly shut. Animals exposed to salinities of 30, 40 and 50 had a faster mortality rate than those at 60 and 70 (Fig. 2A). However, within 5 days there was $100 \%$ mortality in all treatments above 20 (Fig. 2A).

A wider salinity tolerance was recorded when Esengeni mussels were gradually exposed to a rise in salinity. Animals increased their tolerance to include salinity levels from 30 to 50 (Fig. 2B). Previously those exposed to 30, 40 and 50 had 100\% mortality within 4 days, yet with a gradual acclimation animals were able to survive these salinities indefinitely. However, the long-term survival of animals at 50 is unknown, as they had a $73 \%$ survival at the end of the experiment (after 30 days). Animals in these three treatments showed movement and were attached to the edge of experimental bottles. Mussels were still unable to survive extreme salinities, 60 and 70, regardless of the slow acclimation to test conditions (Fig. 2B). Mussels gradually acclimated to the 70 treatment died during the acclimation phase of the experiment. Additionally, the majority of mussels in the 60 treatment died during the acclimation phase, with $100 \%$ mortality reached within 3 days. This was less than the 5 days they were able to survive in the shock experiment (Fig. 2A).

Animals collected from Lister's Point and exposed to a rapid change in salinity showed a similar trend to the Esengeni mussels acclimated to test conditions. They were able to tolerate lower salinities, from 0 to 40 (Fig. 2C). Mortality was seen in the 60 and 70 treatments, similar to that observed in both Esengeni shock and gradually acclimated animals (Fig. 2A, B and C). Activity was recorded in all treatments below 50, however above this salinity mussels were tightly shut. In the salinity treatment of 50, mussels experienced $100 \%$ mortality within five days, while complete mortality was reached faster in the 60 and 70 treatments, after 4 and 3 days, respectively.

Again, mussels exposed to a gradual increase towards test conditions showed a higher tolerance range than animals exposed to a rapid change in salinity. However, the treatments of 60 and 70 were still lethal regardless of the site of collection or exposure method. Additionally, these animals were unable to survive the full acclimation period and did not reach the onset of the experiment. This was similar to the pattern observed with the gradually acclimated Esengeni mussels. Mussels were able to tolerate the salinity treatment of 50 (Fig. $2 \mathrm{D})$, while $100 \%$ mortality occurred within 5 days in the 


\begin{tabular}{|c|c|c|c|c|c|c|c|}
\hline & $\begin{array}{l}\text { Repeated-m } \\
\text { ween salinity } \\
\text { Lister's Point }\end{array}$ & $\begin{array}{l}\text { asures ANOVA comparing } \\
\text { ind exposure time on the } \\
\text { over a } 30 \text {-day period. All G }\end{array}$ & $\begin{array}{l}\text { TABLE } \\
\text { effects } \\
\text { rvival o } \\
\text { hhouse }\end{array}$ & $\begin{array}{l}\text { inity, } \\
\text { chidon } \\
\text { ser cor }\end{array}$ & $\begin{array}{l}\text { osure time a } \\
\text { virgiliae col } \\
\text { ted probab }\end{array}$ & $\begin{array}{l}\text { the in } \\
\text { ted at } \\
\text { es wer }\end{array}$ & $\begin{array}{l}\text { tion } \\
\text { geni and } \\
001 .\end{array}$ \\
\hline Site & Experiment & Source of variation & SS & df & Adjusted df & MS & $F$ \\
\hline & & Exposure time & 1356 & 35.0 & 2.27 & 598 & 393 \\
\hline & Shock & Salinity & 2897 & 7.00 & - & 413 & 4585 \\
\hline ฮั & & Exposure time X Salinity & 904 & 15.9 & - & 56.9 & 37.4 \\
\hline Ф & & Exposure time & 51.7 & 35.0 & 1.86 & 27.7 & 11.2 \\
\hline & Acclimation & \begin{tabular}{|l|} 
Salinity \\
\end{tabular} & 2541 & 4.00 & - & 625 & 141 \\
\hline & & Exposure time X Salinity & 75.4 & 7.45 & - & 10.1 & 4.09 \\
\hline & & Exposure time & 787 & 35.0 & 1.85 & 425 & 744 \\
\hline$\stackrel{\Xi}{.}$ & Shock & \begin{tabular}{|l|} 
Salinity \\
\end{tabular} & 5140 & 7.00 & - & 734 & 11130 \\
\hline$\frac{0}{\circ}$ & & Exposure time X Salinity & 1334 & 13.0 & - & 103 & 179 \\
\hline 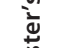 & & Exposure time & 68.8 & 35.0 & 2.16 & 31.8 & 18.0 \\
\hline$\frac{\bar{n}}{3}$ & Acclimation & \begin{tabular}{|l|} 
Salinity \\
\end{tabular} & 2541 & 3.00 & - & 1204 & 783 \\
\hline & & Exposure time X Salinity & 107 & 6.49 & - & 16.5 & 9.31 \\
\hline
\end{tabular}

Lister's Point shock experiment. Although the 60 treatment was still lethal for mussels, animals were capable of withstanding it for 6 days, as opposed to the 4 days previously recorded in the shock experiment. Similarly, not all animals survived until the end of the acclimation process and the majority of animals were dead within $24 \mathrm{~h}$ in the 60 treatment (Fig. 2D).

Overall B. virgiliae appeared to have a preferred tolerance ranging from 0 to 20 , regardless of where they were collected. An increase in tolerance to raised salinities was seen in those collected from sites with a higher salinity (i.e. Lister's Point). In addition, an increase in tolerance was seen when animals were slowly exposed to an increase in salinity over a period of a month for both Esengeni and Lister's Point mussels. Salinity, exposure time and the combination of the two had a significant effect on the survival of $B$. virgiliae in all four experiments (Table 1).

\section{DISCUSSION}

Estuaries are characterised by large temporal and spatial fluctuations in physico-chemical parameters due to dynamic hydrological cycles. Thus, in order to successfully manage an estuary, it is essential to understand how the ecosystem will be affected by different climatic scenarios (Lester and Fairweather, 2009). In Lake St Lucia, salinity fluctuations are fundamental in determining the distribution and abundance of estuarine fauna and flora (Forbes and Cyrus, 1993). This is evident in the shift in bivalve dominance from Solen cylindraceus (dry period) to Brachidontes virgiliae (wet period). In addition, there has been a recent change in distribution ranges, with $S$. cylindraceus previously restricted to the South Lake, but currently established only in the northern reaches (salinity $\approx 20$ ). Brachidontes virgiliae, previously abundant in the Narrows, has now become ubiquitous throughout the system. Nel et al. (2011) determined an experimental salinity tolerance of between 15 and 65 for S. cylindraceus. Acclimation to a gradual decrease in salinity allows this bivalve to survive salinities as low as 10, although long-term survival under such conditions is unknown (Nel et al., 2013). Lake St Lucia is currently in a wet phase, resulting in S. cylindraceus being unable to tolerate the predominantly oligohaline environment dominating the system. This has allowed the Brackwater mussel, B. virgiliae, to become dominant throughout Lake St Lucia. Weerts (1993) described a similar situation during periods of low salinity, when B. virgiliae was considered the most abundant bivalve, while S. cylindraceus was rare. According to results obtained with the current in-vitro study, $B$. virgiliae has a salinity tolerance skewed towards the lower levels, and is able to tolerate virtually freshwater conditions. This mussel thrives in Lake St Lucia during the wet period, as it has a preferred tolerance range from freshwater to 20 .

Brachidontes virgiliae is a minute, epifaunal mussel regularly underestimated in macrofaunal surveys, with only anecdotal evidence available on its salinity tolerance. Day et al. (1954) found B. virgiliae at salinity levels ranging from 26.0 to 34.1 . This is similar to the results obtained by Blaber et al. (1983), showing the presence of this mussel in South Lake under stable marine salinities. It has been described as a euryhaline species commonly found in the salinity range of 34.4-36.0 (Millard and Broekhuysen, 1970). Absent or rare during periods of hypersalinity, the species has, however, a preference for low salinities (Boltt, 1975). Davies (1980) suggested a tolerance range from 0 to 34 for mussels found in the Kowie Estuary, Eastern Cape, South Africa, although there had at that time been no attempt to experimentally determine their salinity tolerance. This range is consistent with the results obtained in the present study using mussels collected from Lister's Point and exposed to a rapid change in salinity (salinity tolerance: 0 to 40; Fig. 2C). In addition, mussels collected from both Esengeni and Lister's Point and gradually exposed to an increase in salinity showed a slightly wider salinity range, which included the 50 treatment (Fig. 2B and D). Although there is no evidence of $B$. virgiliae establishing outside of its natural distributional range, it is a potential biofouling threat given its wide salinity tolerance and ability to attach to boats' hulls.

Tolerance limits have been extended in numerous bivalve species by acclimation (Castagna and Chanley, 1973). Berger and Kharazova (1997) stated that sensitivity to environmental fluctuations may be shifted by previous acclimation to low/high salinity. In this study, a wider salinity tolerance range was seen in mussels collected from the site exhibiting the higher saline environment. In addition, an increase in tolerance was seen when animals were slowly exposed to an increase in salinity over a monthly period. A wider salinity tolerance was also seen for S. cylindraceus when gradually increased/decreased to test conditions (Nel et al., 2011). Numerous studies have illustrated an increase in the salinity tolerance of bivalve species when slowly adjusted to test salinities (Yuan et al., 2010). Additionally, the historical fluctuations observed within False 
Bay are wider than those occurring at Esengeni. This may be reflected in the evolutionary response that species have to a change in environmental parameters.

This mussel is often found attached to submerged macrophytes (Nel et al., 2012). In Lake St Lucia, the three main macrophyte species are Stukenia pectinata, Ruppia cirrhosa and Zostera capensis (Adams and Bate, 1994). Floods may dislodge these submerged macrophytes and this will have an indirect effect on the mussel population. An increase or dramatic decrease in salinity may also affect $B$. virgiliae indirectly, by eliminating these macrophytes. Stukenia pectinata is excluded above salinity levels of $20 ; Z$. capensis can tolerate salinity levels between 10 and 45, while $R$. cirrhosa is able to tolerate salinities as high as 50 (Adams and Bate, 1994; Adams et al., 2013).

Salinity may affect an organism directly through its physiology and indirectly by altering its food, predators and habitat availability (Finney, 1979; Jassby et al., 1995; Montagna et al., 2002). The metabolic rates of an organism are affected with escalation in its activity level (Berger and Kharazova, 1997; Segnini de Bravo et al., 1998). In mussels, the formation of byssus threads can be affected by changes in the saline environment (Sundaram and Syed Shafee, 1989). Although these factors were not directly measured in this study, a reduction in mobility was observed under unfavourable salinity levels. Additionally, mussels in the higher treatments did not attach to the sides of the incubation vessel, as opposed to their counterparts exposed to lower salinities. There is a need for future research to focus on sub-lethal effects of salinity on attachment, filtration and respiration, as these factors will affect population dynamics.

Sessile and relatively sedentary species are unable to move away from unfavourable environmental conditions (Perkins, 1974). They thus employ behavioural strategies to cope with exposure to salinity levels outside of their tolerance range. Mussels may close their shells when exposed to abnormal salinities, with this isolation reflex first occurring in the more sensitive individuals and later in all (Berger and Kharazova, 1997). Individuals are able to withstand prolonged asphyxia and accumulation of acidic products produced during anaerobic metabolism, while the mussel remains closed (Berger and Kharazova, 1997). However, this is a temporary mechanism and long-term survival under such conditions is unlikely. Zebra mussels are extremely starvation-tolerant and this may be a mechanism used to withstand periods of closure (McMahon, 1996). In the current study, B. virgiliae displayed an ability to withstand unfavourable conditions for a few (4 to 7) days by tightly closing their shells. Although long-term survival at these salinity levels is unlikely, this mussel may be able to tolerate short spikes in the saline environment.

Lake St Lucia is characterised by floods, wetter than average years and periods of extreme drought conditions. Floods such as those caused by Cyclone Domoina in January/February 1984 reduced the salinity within Lake St Lucia from $\sim 40$ to nearfreshwater conditions, in a matter of days (Cyrus, 1988; Forbes and Cyrus, 1993; Nel et al., 2011). This cyclonic activity and heavy rains caused a reduction in the macrofaunal density by 40\% (Cyrus, 1988). Owen and Forbes (1997) found that macrofaunal biomass declined following cyclonic activity. Prolonged periods of rainfall will also cause a decline in salinity, thus eliminating species unable to withstand oligohaline to limnetic conditions (Owen and Forbes, 1997). There is often a moderate to large decrease in abundance (e.g. 28 to 100\%) of certain species, especially bivalves, when exposed to a drastic decrease in salinity (McLachlan and Erasmus, 1974; Hanekom, 1989; Kanandjembo et al., 2001). Although Lake St Lucia has historically been subjected to cyclonic activity (Cyrus, 1988; Owen and Forbes, 1997), an increase in the frequency of occurrence and intensity of extreme events is expected in response to climate change (Schulze, 2006). Brachidontes virgiliae may be positively affected by the dramatic decrease in salinity; however, an associated high silt load entering the system may have detrimental effects on filter-feeding mussels (Adam, 1986; Thrush et al., 2004). Although B. virgiliae may withstand periods of about 30 days of exposure to high silt concentration, up to $1500 \mathrm{NTU}$ (HA Nel, unpubl. data), this needs to be investigated further.

Lake St Lucia has recently experienced a severe drought period that has resulted in the development of a reverse salinity gradient and caused hypersaline events in the northern reaches. High salinities prevailing in False Bay and North Lake have resulted in a scarcity of benthic fauna and flora (Day et al., 1954). Similarly, in the late 1960s, Millard and Broekhuysen (1970) attributed the observed decrease in faunal richness in the northern reaches to extreme conditions. In addition, Boltt (1975) reported that an impoverished benthic community was seen when there were high salinities, between 45 and 80 . Pillay and Perissinotto (2008) suggested that the reduction in macrofaunal abundance, species richness and diversity in the northern parts of the system was due to hypersaline conditions and low water levels. Thus localised elimination due to hypersaline conditions is well documented, whereby species that are unable to tolerate high salinities are temporarily eliminated from the system. Brachidontes virgiliae is able to withstand salinity levels up to 50, if slowly acclimated or found in a habitat with higher salinities. Above 50, this species remains tightly shut and suffers mass mortality within a week. Both S. cylindraceus and B. virgiliae have a wide salinity tolerance that has enabled these species to persist, whereas numerous bivalves have previously been eliminated from this system due to unfavourable conditions (Nel et al., 2011; Nel et al., 2012).

In conclusion, this species is unlikely to disappear from Lake St Lucia, as it becomes widespread during wet periods, and is able to withstand low salinities. During dry periods, it remains abundant in the Narrows and is restricted to areas with salinity levels below 50. During the most extreme drought periods, when salinities may reach 200 in the northern reaches, the Narrows would act as a refuge area for this mussel. This is in contrast to S. cylindraceus which uses South Lake as its reservoir during hypersaline conditions and the northern reaches during oligohaline conditions. Lancaster and Belyea (1997) described a refuge as an area that provides a species with protection from the negative effects of the surrounding environment. These areas are important during natural disturbances (i.e. drought and flood events), as they allow species to persist in a highly variable ecosystem (Magoulick and Kobza, 2003). Future studies should investigate the rate at which these areas act as nuclei from which recolonisation of the remaining lake can occur once favourable conditions have returned.

\section{ACKNOWLEDGEMENTS}

We are grateful to the iSimangaliso Park Authority and Ezemvelo KZN Wildlife for supporting this project. Funding for this project was provided by the National Research Foundation (NRF, Pretoria) through the programme Knowledge Fields Development - Society, Ecosystems and Change (SEACHANGE), as well as the South African Netherlands Research Programme on Alternatives in Development (SANPAD, Durban) and the University of KwaZulu-Natal (UKZN, Durban). Thanks to Nicola Carrasco and David Dyer for assisting with the 
collection of animals at Lake St Lucia and John Swart for assisting with the execution of the experiments in the laboratory.

\section{REFERENCES}

ADAM ME (1986) The Nile bivalves - how do they avoid silting during the flood? J. Mollusc. Stud. 52 248-252.

ADAMS JB and BATE GC (1994) The ecological implications of tolerance to salinity by Ruppia cirrhosa (Petagna) Grande and Zostera capensis Setchell. Bot. Mar. 37 449-456.

ADAMS JB, NONDODA S and TAYLOR RH (2013) Macrophytes. In: Perissinotto R, Stretch DD and Taylor RH (eds.) Ecology and Conservation of Estuarine Ecosystems: Lake St Lucia as a Global Model. Cambridge University Press, New York.

BEGG GW (1978) The Estuaries of Natal. (Part II). Natal Town and Regional Planning Commission Report 41.657 pp.

BERGER VJ and KHARAZOVA AD (1997) Mechanisms of salinity adaptations in marine molluscs. Hydrobiologia 355 115-126.

BLABER SJM, KURE NF, JACKSON S and CYRUS DP (1983) The benthos of South Lake, St Lucia following a period of stable salinities. S. Afr. J. Zool. 18 311-319.

BOLTT RE (1975) The benthos of some southern African Lakes Part $\mathrm{V}$ : The recovery of the benthic fauna of St Lucia Lake following a period of excessively high salinity. Trans. R. Soc. S. Afr. 41 295-323.

CARRASCO NK and PERISSINOTTO R (2012) Development of a halotolerant community in the St. Lucia Estuary (South Africa) during a hypersaline phase. Plos One 7 1-14.

CASTAGNA M and CHANLEY P (1973) Salinity tolerance of some marine bivalves from inshore and estuarine environments in Virginia waters on the western mid-Atlantic coast. Malacologia 12 47-96.

CYRUS DP (1988) Episodic events and estuaries: Effects of cyclonic flushing on the benthic fauna and diet of Solea bleekeri (Teleostei) in Lake St Lucia on the southeastern coast of Africa. J. Fish Biol. 33 $1-7$.

CYRUS DP, VIVIER L and JERLING HL (2010) Effect of hypersaline and low lake conditions on ecological functioning of St Lucia estuarine system, South Africa: An overview 2002 - 2008. Estuar. Coast. Shelf Sci. $86535-542$.

DAVIES BR (1980) The identification of the mytilids Musculus virgiliae Barnard, Arcuatula capensis (Krauss) and Brachidontes variabilis Krauss, with corrections to the literature and a note on their distribution. Trans. R. Soc. S. Afr. $44225-235$.

DAY JH, MILLARD NAH and BROEKHUYSEN GJ (1954) The ecology of South African estuaries Part IV: the St Lucia system. Trans. R. Soc. S. Afr. 34 129-156.

FINNEY CM (1979) Salinity stress in harpacticoid copepods. Estuaries 2 132-135.

FORBES AT and CYRUS DP (1992) Impact of a major cyclone on a southeast African estuarine lake system. Neth. J. Sea Res. 30 265-272.

FORBES AT and CYRUS DP (1993) Biological effects of salinity gradient reversal in a southeast African estuarine lake. Neth. J. Aquat. Ecol. 27 485-488.

HANEKOM N (1989) A note on the effects of a flood of medium intensity on macrobenthos of soft substrata in the Swartkops Estuary, South Africa. S. Afr. J. Mar. Sci. 8 349-355.

JASSBY AD, KIMMERER WJ, MONISMITH SG, ARMOR C, CLOERN JE, POWELL TM, SCHUBEL JR and VENDLINSKI TJ (1995) Isohaline positions as a habitat indicator for estuarine populations. Ecol. Appl. 5 272-289.

KANANDJEMBO AN, PLATELL ME and POTTER IC (2001)The benthic macroinvertebrate community of the upper reaches of an Australian estuary that undergoes marked seasonal changes in hydrology. Hydrol. Process. 15 2481-2501.

LANCASTER J and BELYEA LR (1997) Nested hierarchies and scaledependence of mechanisms of flow refugium use. J. N. Am. Benthol. Soc. 16 221-238.
LESTER RE and FAIRWEATHER PG (2009) Modelling future conditions in the degraded semi-arid estuary of Australia's largest river using ecosystem states. Estuar. Coast. Shelf Sci. 85 1-11.

MAGOULICK DD and KOBZA RM (2003) The role of refugia for fishes during drought: a review and synthesis. Freshwater Biol. 48 1186-1198.

MCLACHLAN A and ERASMUS T (1974) Temperature tolerances and osmoregulation in some estuarine bivalves. Zool. Afr. 9 1-13.

MCLEOD R and WING S (2008) Influence of an altered salinity regime on the population structure of two infaunal bivalve species. Estuar. Coast. Shelf Sci. 78 529-540.

MCMAHON RF (1996) The physiological ecology of the zebra mussel, Dreissena polymorpha, in North America and Europe. Am. Zool. 36 339-363.

MILLARD NAH and BROEKHUYSEN GJ (1970) The ecology of South African estuaries Part X: St Lucia: a second report. Zool. Afr. 5 277-307.

MONTAGNA PA, KALKE RD and RITTER C (2002) Effect of restored freshwater inflow on macrofauna and meiofauna in upper Rincon Bayou, Texas, USA. Estuaries 25 1436-1447.

NEL HA, PERISSINOTTO R, TAYLOR RH and CARRASCO NK (2011) Salinity tolerance of the bivalve Solen cylindraceus (Hanley, 1843) (Mollusca: Euheterodonta: Solenidae) in the St Lucia Estuary. Afr. Invert. 52 575-586.

NEL HA, PERISSINOTTO R and TAYLOR RH (2012) Diversity of bivalve molluscs in the St Lucia Estuary, with an annotated and illustrated checklist. Afr. Invert. 53 503-525.

NEL HA, PERISSINOTTO R and TAYLOR RH (2013) In situ growth rate of Solen cylindraceus (Mollusca: Euheterodonta: Solenidae) in the St Lucia estuarine lake, South Africa. Afr. Zool. 48 266-273.

OWEN RK and FORBES AT (1997) Salinity, floods and the infaunal macrobenthic community of the St Lucia Estuary, KwaZulu-Natal, South Africa. Afr. J. Aquat. Sci. 23 14-30.

PERKINS EJ (1974) The Biology of Estuaries and Coastal Waters. Academic Press, London. 678 pp.

PILLAY D and PERISSINOTTO R (2008) The benthic macrofauna of the St Lucia Estuary during the 2005 drought year. Estuar. Coast. Shelf Sci. 77 35-46.

ROLSTON A and DITTMANN S (2009) The Distribution and Abundance of Macrobenthic Invertebrates in the Murray Mouth and Coorong Lagoons 2006 to 2008. Water for a Healthy Country National Research Flagship. CSIRO, Canberra.

SCHULZE RE (2006) Climate Change and Water Resources in Southern Africa. WRC Report No. 1430/1/05, Water Research Commission, Pretoria.

SEGNINI DE BRAVO MIS, CHUNG KS and PEREZ JE (1998) Salinity and temperature tolerances of the green and brown mussels, Perna viridis and Perna perna (Bivalvia: Mytilidae). Revista De Biol. Trop. 46 121-125.

SUNDARAM KS and SYED SHAFEE M (1989) Salinity tolerance of some bivalves of Ennore estuary. J. Mar. Biol. Assoc. India 31 299-302.

THRUSH SF, HEWITT JE, CUMMINGS V, ELLIS JI, HATTON C, LOHRER A and NORKKO A (2004) Muddy waters: elevating sediment input to coastal and estuarine habitats. Front. Ecol. Environ. 22 99-306.

WEERTS KA (1993) Salinity, sediments and the macrobenthic communities of Lake St Lucia. MSc Thesis, University of Natal, Durban.

WHITFIELD AK, BATE GC, FORBES T and TAYLOR RH (2013) Relinkage of the Mfolozi River to the St Lucia estuarine system urgent imperative for the long-term management of a Ramsar and World Heritage Site. Aquat. Ecosyst. Health Manage. 16 104-110.

WHITFIELD AK and TAYLOR RH (2009) A review of the importance of freshwater inflow to the future conservation of Lake St Lucia. Aquat. Conserv.: Mar. Freshwater Ecosyst. 19 838-848.

YUAN W, WALTERS LJ, SCHNEIDER KR and HOFFMAN EA (2010) Exploring the survival threshold: A study of salinity tolerance of the non-native mussel Mytella charruana. J. Shellfish Res. 29 415-422. 